\title{
Growth and Training Impact in IT: A Measure of Ethical Reasoning
}

\author{
Belle Woodward, Assistant Professor, Southern Illinois University, bellew@siu.edu
}

\begin{abstract}
As technological advances reshape society and the workplace, the need for ethically-grounded information technology professionals has become paramount. Recognizing the importance of pursuing the ethical life as well as the unique ethical challenges posed by rapidly evolving technologies, scholars have recently debated how best to incorporate ethical instruction in the information technology (IT) curriculum. The controversy lies not so much in whether ethics should be taught, but rather in how to evaluate the effectiveness of particular pedagogical practices vis-à-vis their impact on the ethical development of IT students. One ethicist, Muriel Bebeau, suggests that a system of "intermediate concepts" should be adopted in particular disciplines. This review of the literature traces the developing demand for and concern about ethical training in the IT field and suggests an application of Bebeau's intermediate stages theory in the IT field.
\end{abstract}

\section{INTRODUCTION}

During the last century, technological advances have dramatically reshaped the workplace and have changed the ways in which we communicate individually and globally. With the increasing risk of network intrusions, computer crimes, and information wars, ethical actions among Information Technology (IT) professionals have become all the more important. In large measure, IT educators bear the responsibility not only for cultivating a sense of the importance of ethical action in the next generation of IT professionals, but also for equipping future IT practitioners with the knowledge and skills necessary to address these problems ethically. A central concern for educators is whether their pedagogical practices will enable learners to acquire and apply the set of theoretical and practical skills that represent the core knowledge of a discipline. As a discipline, IT lacks not only research in best practices for ethics training, but also a metric to assess the effectiveness of various pedagogical practices aimed at improving the capacity of students to engage in ethical reasoning. As schools, universities, and government agencies continue to develop ethics curricula and training programs, it has been slowly dawning on IT instructors and trainers that a better measure of learning is a to ensure that the time and effort put into developing curricula and materials for ethics instruction does indeed lead to their intended outcome: improvement of ethical reasoning and increased frequency of ethical behavior. This literature review provides a discussion of the theoretical foundations of ethics while reviewing the evolution of assessment of ethics instruction in the IT discipline. Next, the author will describe the current state of ethics assessment in the IT discipline while proffering a practice-oriented, discipline-specific approach to the assessment of growth or change in ethical reasoning skills, concept acquisition, and process knowledge.

\section{SURVEY OF THE LITERATURE}

\section{Theories of Moral Development and Assessment Tools}

Before turning to a discussion of assessment practices within the context of ethics instruction, it is important to review the relevant theoretical frameworks that inform contemporary instruction and assessment practices. Many consider Lawrence Kohlberg's (1958, 1964, 1967, and 1969) work as some of the most influential research focusing on moral development in student population. Kohlberg's work is particularly relevant because it synthesizes cognitive and moral development. For Kohlberg, ethical development is a function of learning, in that cognitive growth creates a "state of readiness" that is necessary for moral development (Walker, 1988, p. 53). Implicit in Kohlberg's model is the idea that moral judgment is not static, but moves along a developmental trajectory from less to more sophisticated moral positions. This model is important because if ethical development were impossible, instruction would be irrelevant, and assessment would be unnecessary.

Kohlberg's model progresses through six stages, each embedded in one of three levels (i.e., preconventional, conventional, and post-conventional). As a whole, Kohlberg's six stages describe students' movement from highly ego-centric concerns (e.g., the avoidance of punishment), through a stage of decision-making based on what others expect or rules require, to a view of morality based on universal principles such as equality, justice, and human rights. Kohlberg's research also focused on individual autonomy and decision-making using social standards. 
In this way, Kohlberg's work centers on moral reasoning as an understanding of abstract social rights and obligations.

Since Kohlberg, many researchers have borrowed from or expanded upon his work, including Gilligan (1977) and Rest (1979). Carol Gilligan continued Kohlberg's research by expanding the model to include the specific developmental stages of female students. While Kohlberg focused on individual autonomy and decision-making using social standards, Gilligan's work looked at how relationships with others influence moral decision making. Gilligan's three-stage model maps a female's ethical evolution from a self-centered preoccupation with survival, to engagement and reliance on others, and finally to decision-making based on the balance between selfneeds and cares for others (Gilligan, 1977).

Like Kohlberg, Rest articulates a six stage model of moral development, but unlike Kohlberg, Rest rejects definitive, lock-step stages, arguing instead, that individuals move fluidly between stages. For Rest, individuals may develop in more than one stage at a time. Therefore, Rest's stages are not strictly hierarchical, but reflect a belief in moral development as a continuous, fluid process.

Taken together, the work of Kohlberg, Rest, and Gilligan provides important insights into how ethical reasoning develops in individuals. Collectively their work has provided the theoretical foundation for a generation of assessment instruments, including Kohlberg's Moral Judgment Interview and the Defining Issues Test (DIT) (Pascarella \& Terenzini, 1991). The Moral Judgment Interview (MJ) (Colby et al, 1987) features three hypothetical dilemmas followed by a series of probing questions designed to elicit a picture of the interviewee's capacity for moral reasoning. During the assessment, the interviewee is asked (via probing questions) to justify his or her response to the test's hypothetical situation. The interview is then scored using a standardized classification system designed to assess the structure of the interviewee's reasoning rather than the quality of his or her response (Pascarella \& Terenzini, 1991).

The DIT (Rest, 1986) is a paper-pencil exam that uses six hypothetical dilemmas similar to those used in the MJI. Each dilemma is followed by twelve interpretive statements about the dilemmas. Respondents rate and rank the statements, which are linked to a stage of either Rest's or Kohlberg's moral development model in terms of how each would influence their decision-making. Because the DIT is administered on paper, it can be quickly and objectively scored (Pascarella \& Terenzini, 1991). The DIT scores reflect the relative importance participants give to "post-conventional” or "principled" justification (i.e. Kohlberg's highest level of moral reasoning). Higher scores indicate that the individual is more morally developed. Rest et al., (1999) assert that the DIT has proved itself valid and reliable in hundreds of studies. This conclusion is supported in part by a mega-sample comprised of 45,856 DITs scored from 1989 through 1993 that evidence the DIT's validity and reliability in spite of differences in age and cultural background of participants as well as the region where the tests were administered. In addition, the DIT significantly predicts real-life moral behavior (Rest et al., 1999). Cronbach alphas for the DIT are in the upper 0.70s and lower 0.80s and test / re-test reliability is commensurate (Rest \& Narvaez, 1998).

Though both the DIT and the MJI assess moral reasoning, they differ in the tasks they ask participants to complete. The MJI is “a production task" - that is, it asks individuals to produce verbal responses to a set of questions (Evans, Forney \& Guido-DiBrito, 1998). In contrast, the DIT is "a recognition task" that provides respondents with a set of possible responses. DIT respondents are then asked to identify the responses that most closely mirror their thinking. Because of this difference, DIT assessments are "consistently more varied and more sensitive to higher-stage reasoning than those obtained from Kohlberg's Moral Judgment Interview” (Evans et al, 1998, p. 180).

Recently, the Center for the Study of Ethical Development at the University of Minnesota created a second version of the DIT, called the DIT-2 (Rest et al, 1999). This updated version of the DIT contains new scenarios, and it is also shorter than the original version (with five ethical dilemmas rather than six). Although the DIT-2 was developed to measure general moral development, it has been found to measure moral development in many types of educational programs including medicine, business, public administration, and law (Bebeau, 2002; Rizzo \& Swisher, 2004). As with its predecessor, the DIT-2 asks respondents to choose between twelve responses that reflect Kohlberg's stages of moral development. The Scoring of the DIT-2 yields an index score (N2). A key feature of this index is that higher stage reasoning is prioritized and lower stage reasoning is rejected by the test. The test accounts not only for ranked items that reflect post-conventional moral reasoning, but also for rated items which reflect respondents' preferences for higher versus lower stage reasoning. In validity testing, DIT-2 results have been 
comparable to the original DIT. In addition to the practical advantages of shortened length and updated language, the DIT-2 has correlated positively with the original DIT $(r=0.79)$ and has also proven internally reliable (Cronbach's alpha $=.81$ ) (Rest et al., 1999). In short, the DIT-2 does not sacrifice validity and may actually improve validity through its updated construction (Rest \& Narvaez, 1998). With its new scoring indices (N2) and subject reliability checks, the DIT-2 demonstrates the same validity as the original DIT (Rest \& Narvaez, 1998).

\section{Ethics Education and Assessment}

Despite the reliability and validity of the DIT-2, researchers who have used the DIT-2 to assess their instructional interventions have had mixed results. For example, Drake et al. (2005) considered two approaches to teaching ethics within an engineering program for undergraduate students. These researchers developed and administered a semester-length ethics course for engineering students, and compared the performance of students in that course with the performance of students whose only exposure to ethical training came in the form of an ethics module included in a typical engineering course. To assess the differences between the two programs, researchers used the DIT-2. In reflecting upon their use of the DIT-2, Drake et al. commented that "the DIT-2 measures only one component of moral conduct; while it is surely important to help students improve their moral judgment, it is just as important to foster students' ability to recognize situations that call for ethical judgment” (2005, p. 22). Drake et al.’s primary concern was that while students may be able to identify ethical concerns in the abstract testing situation, those same students may be unable to apply that knowledge to everyday situations that call for moral action. And yet an individual must transfer his or her abstract knowledge to immediate situations if he or she is to solve ethical dilemmas. According to Drake et al, the DIT-2 inadequately measures this immediate readiness.

Intermittently, other researchers who have used the DIT or DIT-2 to measure short-term growth in moral development for students in their ethics program have also complained about problems with these instruments. Woodward, and Ashby (2006), for example, used the DIT-2 to assess the difference in ethical development between students engaged in case method discussions and a control group of student exposed to lecture-discussion. Their results indicated no difference between the groups, and they posit that the DIT2 is not sensitive enough to reflect discipline-specific ethical development over a treatment period of short duration. These same researchers also suggest that it would be "beneficial to develop a new instrument, perhaps modeled on the DIT-2, incorporating ethical dilemmas more particular to the field of information systems technology” (p. 7). Similarly, Harris, Pritchard and Rabins (2000) examined the effects of case-method instruction on undergraduate information technology students. These researchers noted a need to consider an approach to ethics instruction that is more discipline-centered. Harris et al. reflected that "there is a further problem that a general measure of moral judgment may not reflect the disciplinespecific judgment that may be required in professional settings” (p. 142).

In another similar study, Staehr and Byrne (2003) provided university students with a treatment of an ethical dilemma discussion and compared the shortterm ethical development of this group with a control group. These researchers suggest that further work is required in developing moral reasoning assessments, with a focus on creating specialty or profession oriented dilemmas. Current moral reasoning assessments like the DIT do not draw from profession specific dilemmas in building assessment tool content.

Rizzo and Swisher (2004) noting significant use of two survey instruments, decided to test the validity of the Stewart-Sprinthall Management Survey and the Defining issues Test. They asked members of the American Society for Public Administration Ethics Section to take both surveys. Rizzo and Swisher's findings led them to posit, that the DIT-2 may be more effective to "evaluate the outcomes of educational interventions and to compare groups against established norms" (p. 346). They also argued that the DIT-2 scenarios are intrinsically social and political, which may have influenced their results.

Bebeau and Thoma (1999) echo others in disputing the validity of the original DIT. These researchers assert that the DIT is an inadequate measure of shortterm progress. However, they note that its inadequacy is not related to the "outdated" or "unfamiliar" scenarios used in the test, but, instead, to the widely encompassing and "highly abstract markers" (p.347) used in the instrument. In short, because the DIT-2 is designed around Kohlberg's stages of moral development, it is relatively blunt. Kohlberg's work describes abstract and universal principles, and it is often difficult to translate abstract ethical knowledge into concrete ethical action. Like Woodward et al, Bebeau and Thoma argue for discipline specific instruments as a means of more accurately assessing student's ethical and moral development. 
Many ethics education programs have been assessed using the DIT and the DIT-2 (King \& Mayhew, 2002). A survey of abstracts posted on the National Science Foundation (NSF) website regarding currently funded NSF-projects found that many current research projects employ the DIT-2 instrument for assessment purposes; as a pre-/post instrument used to measure ethical growth after a treatment of less than six months to one year (National Science Foundation Project Abstracts, 2005). Currently, the NSF is supporting various research projects in the area of ethics education for graduate students in science and engineering. At least five current NSF projects address the development of instructional materials aimed at graduate-level ethical education in science, engineering and technology. The instructional materials to be developed from these NSF-funded projects will employ varied instructional methodologies, such as case-method studies, on-line interactive decision spaces, cooperative learning-based modules, a problem-based learning approach to ethics instruction, and a cross-cultural and cross-discipline lecture approach. Many of these projects have proposed using the DIT-2 to assess the effectiveness of the instructional strategies being researched. Concern needs to be raised regarding the adequacy of the DIT-2 as a measure of short-term ethical development. Given the importance of safety and security in information technology, targeted instruction is insufficient for ensuring that aspiring IT professionals are prepared for the ethical demands they will one day face. Instead, instruction must be paired with assessment: an appropriate instrument that measures incremental growth in ethical reasoning and behavior.

Refining Ethics Assessment: Intermediate Concepts During the development and testing of the DIT, Rest (1983) conceived of a model of morality that encompassed not only moral judgment but also moral sensitivity, character, and competence. Such a nuanced model recognizes that the understanding brought by an individual to the resolution of a complex moral problem develops in conjunction with each individual's personal development. Furthermore, Rest posits that the following four components are necessary prerequisites to moral behavior. First, individuals must have the sensitivity to interpret certain situations as moral. Second, individuals must be able to judge which actions are justified. Third, individuals must prioritize such that moral concerns take precedence over other significant concerns. Finally, individuals must exhibit moral character such that they follow through with actions that are their moral choice.
Rest's work is significant because it extends the conversation about ethical development from moral reasoning (the focus of Kohlberg's work) to moral choice and action. Rest argued that moral action requires engagement not only with abstract principles like justice, but also with ethical situations as they occur in everyday experience. According to Bebeau and Thoma, "Rest suggests that we should focus our attention on identifying processes as they contribute to moral action” (1999, p. 345). In addition, Bebeau and Thoma (1999) have noted that "targeting specific deficiencies in each participant proved to be an effective intervention strategy” (p. 346), thus linking instruction and assessment to strategies that will assist participants in their daily lives. Bebeau and Thoma also concluded that each discipline should work toward the development of profession-specific assessments directed at more accurately measuring ethical development not only across all four of Rest's components, but also for both short-term and long-term growth. These profession-specific measures would reflect the content offered in each profession's specialized ethics training and would also provide a more accurate measure of an individual's ethical capacity (Rest, Narvaez, Bebeau, \& Thoma, 1999). In other words, Bebeau and Thoma, working from Rest's position, argue for two important revisions to traditional measurement instruments like the DIT: 1 . they assert that practical, concrete examples should be used in case-method vignettes instead of the abstract concepts typically used; and, 2. concrete examples should be constructed to reflect the issues and challenges specific to that particular discipline. Bebeau and Thoma (1999) call these profession-specific measures "intermediate concepts". Although the literature does not directly proffer these concepts, they can be derived from IT experts as well as from the various published IT codes of ethics. For example, IT intermediate concepts to be considered include personal identity-related data, privacy rights of consumers, and intellectual property rights. They developed their Intermediate Concepts Measure (ICM) for use in dental curriculum.

\section{CONCLUSION}

Despite the proliferation in development of IT training and courses designed to affect ethical reasoning, no appropriate measure has been developed. Assessment strategies have evolved from lengthy interviews (Kohlberg's MJI), to the wide-spread use of the Defining Issues Test and its revised version, the DIT-2. The next steps in assessment should draw from the well-established steps of the DIT and DIT-2, using ethical dilemmas to stimulate ethical thinking, but should be based on discipline-specific intermediate 
concepts rather than more global situations. The development of an intermediate concepts instrument is essential as schools, professional organizations and private companies seek to understand the ethical development of information systems students and professionals. With the availability of such an instrument, IT educators can regularly monitor the effectiveness of their ethics training as well as gauge the ethical growth in their students. IT researchers will also have an instrument capable of more accurately assessing the effectiveness of their proposed intervention.

\section{REFERENCES}

1. Bebeau, M.J. (1994). Influencing the moral dimensions of dental practice. In J. Rest \& D. Narvaez (Eds). Moral Development in the Professions: Psychology and Applied Ethics (pp. 121146). New York: Lawrence Erlbaum Associates.

2. Bebeau, J. M. (2002). The defining issues test and the four component model: Contributions to professional education. Journal of Moral Education, 31(3) 271-295.

3. Colby, A., Kohlberg, L., Speicher, B., Hewer, A., Candee, D., Gibbs, J., \& Power, C. (1987). The Measurement of Moral Judgment: Vol. 2. Standard Issue Scoring Manual. New York: Cambridge University Press.

4. Drake, J. M., Griffin M. P., Kirkman R., \& Swann L. J. (2005). Engineering ethical curricula: Assessment and comparison of two approaches. Journal of Engineering Education, 92(2) 223231.

5. Evans, N.J., Forney, D.S., \& Guido-DiBrito, F. (1998). Student Development in College. San Francisco: Jossey-Bass.

6. Gilligan, C. (1977). In a different voice: Women's conceptions of the self and of morality. Harvard Educational Review, 47(4) 481-571.

7. Harris, C. E., Pritchard, M.S., \& Rabins, M.J. (2000). Engineering Ethics: Concepts and Cases, $2^{\text {nd }}$ ed. Belmont, CA: Wadsworth.

8. King, M. P., \& Mayhew J, M. (2002). Moral judgment development in higher education: Insights from the defining issues test. Journal of Moral Education, 31(3) 247-270.

9. Kohlberg, L. (1958). The development of modes of moral thinking and choice in the 10 to 16 years. Unpublished dissertation, University of Chicago.

10. Kohlberg, L. (1964). Development of moral character and moral ideology. In Hoffman (Ed.). Review of Child Development Research. Vol. 1. New York: Russell Sage Foundation.
11. Kohlberg, L. (1967). Moral and religious education and the public schools: A developmental view. In T. Sizer (Ed.), Religion and Public Education. Boston: Houghton-Mifflin.

12. Kohlberg, L. (1969) Stage and sequence: The cognitive-developmental approach to socialization. In D. Goslin (Ed.), Handbook of Socialization Theory and Research (pp. 341-480). Chicago: Rand McNally.

13. National Science Foundation (2005) Research Project Abstracts [Internet]. Available: http://www.nsf.gov/index.jsp [Accessed 20 February, 2006].

14. Pascarella, E.T., \& Terenzini, P.T. (1991). How College Affects Students. San Francisco: Jossey Bass.

15. Rest, J.R. (1979). Development in moral issues. Minneapolis, MN: University of Minnesota Press.

16. Rest, J.R. (1983). Morality. In P. H. Mussen, (ser. ed.), J Flavell, \& E. Markman (vol. eds)., Handbook of Child Psychology: Cognitive Development, Vol. 3 (pp. 556-629). New York: Wiley.

17. Rest, J.R., Narvaez, D., Bebeau, M.J., \& Thoma, S.J. (1999). Postconventional moral thinking: A neo-Kolhbergian approach, Hillsdale, NJ: Erlbaum Associates.

18. Rest, J.R., Narvaez, D., Thoma, S.J., \& Bebeau, M.J. (1999). DIT-2: Devising and testing a revised instrument of moral judgment. Journal of Educational Psychology, 91(4), 644-59.

19. Rest, J.R., Thoma, J. S., \& Edwards, L. (1997). Designing and validating a measure of moral judgment: Stage, preference and stage consistency approaches. Journal of Educational Psychology, 89(1) 5-28.

20. Rizzo, A., \& Swisher, L.L. (2004). Comparing the Stewart-Sprinthall Management Survey and the Defining Issues Test-2 as measures of moral reasoning in public administration. Journal of Public Administration Research and Theory, 14 (3), 335-348.

21. Walker, L. J. (1988). The development of moral reasoning. Annals of Child Development, 5, 3378.

22. Woodward, B. S, \& Ashby, S. (2006). Measuring growth and impact: Ethical reasoning in the information technology field. Issues in Informaiton Systems. 